\title{
Customizing the Knowledge Flow Across a Firm's Internal Value Chain
}

\author{
Nataly Jhannett Flores Marca \\ University of Southeast Norway \\ Yang-Yang Zhao \\ University of Oslo
}

An effective internal value chain for a firm is to gain competitive advantage, which a large set of resources circulate to add value to final products or service. Knowledge, as a key resource, can circulate across the internal value chain for a firm's better performance. However, there is a lack of a systematic mechanism for a sustainable flow of knowledge across a firm's internal value chain. We develop a customized procedure to ensure an efficient knowledge flow across the firm's internal departments. Based on the literature review and best practices from the case study, a four-step customized procedure is outlined.

\section{INTRODUCTION}

\section{Background}

As knowledge plays an important role in value creation, firms often wish to skew the knowledge flow in their favor. The ineffective knowledge flow can delay the delivering of a product or service to customers (Abecker, 1997). It could be associated with the difficulties to identify what impedes the proper knowledge flow, the lower level of knowledge sharing and the raise of error makings (Klint \&Verhoef, 2002). Other factors that may hinder the efficiency of the knowledge flow include the diversity of terminologies, backgrounds, cultures and languages between the interested parties within a firm (Frey, et al., 2012). The direct consequences are misunderstandings among the interested parties and the increasing time and space used to communicate knowledge within the firm (Dalkir \& Beaulieu, 2017). Therefore, to design a firm's knowledge flow mechanism is crucial yet challenging.

This study is conducted in the context of software development industry. As a fast-growing industry, software firms strive for a high level of competitiveness in the global market. As the customer/user's demands constantly change and increase, software firms are seeking innovative strategies for an improved internal value chain to remain competitive. In a software development, the knowledge is the key element to achieve the customer/user's satisfaction. However, not all the knowledge is well selected to be used and provided effectively.

\section{Firm of Interest}

The firm of this study is a Norwegian company that develops and delivers user-friendly software solutions for project management tools and equipment controls among others. The headquarter of the 
company is located in Norway and has extended its products to other countries. This study mainly took the operations in Norway, Finland, Denmark, Sweden, England, Netherlands, Poland and China offices into consideration.

The firm has been experiencing an accelerated growth since the successful launch and acceptance of its products in the global market. The main product line consists of electronic systems, including both software and hardware. The firm takes the responsibility for the quality and the information security. The product-associated services are based on digital technology. They are offered by a total of 350 people's work across the departments of the internal value chain. The structure of the firm's internal value chain is formed by the departments of development, information technology, research and creativity, marketing, sales, planet service, logistics, customer service, finance, quality and performance.

\section{Problem Statement}

As a rapid growth of business, managing the knowledge becomes more and more crucial for sustainable competitive advantage in global market (Lee \& Han, 2009). A firm's capability to manage knowledge affects the knowledge flow across the interested groups or disciplines. An appropriate knowledge flow ensures the complete, accurate and useful knowledge delivery to achieve customer satisfactions while maintaining its consistency (Wixom \& Todd, 2005).

During product or service development, a lot of new information and knowledge are simultaneously generated. When the product or service knowledge is created, the appropriate knowledge must be able to reach other interested groups of the firm's internal value chain and finally the customers. This means moving knowledge from the place where it is generated to the place where it is needed. The firm usually has a set of implicit activities for transferring the product knowledge across the firm's internal value chain in order to achieve a high level of customer satisfaction. So that the knowledge continuously flows across the departments of the firm's value chain. However, this knowledge flow can be hindered by many factors that cause the use of additional and unnecessary time and effort. Without a systematic system mapping, it is difficult to identify and track those factors. Consequently, the main issue in the firm is the lack of a systematic mechanism to facilitate the management of the knowledge flow across its internal value chain.

\section{Research Objective}

The main objective is to study how to customize a systematic mechanism to facilitate the knowledge flow across a firm's internal value chain for optimized customer satisfaction. From a knowledge management $(\mathrm{KM})$ perspective, we have used a case study approach in problem solving. The research tasks are detailed as follows: (i) to investigate the KM literature and how KM approach can be applied within the internal value chain context; (ii) to identify the current situation of the knowledge flow within the case firm; (iii) to develop a customized procedure that fits the case firm's current needs, as the response to the lack of a mechanism that facilitates knowledge flow.

\section{LITERATURE REVIEW}

Many firms continuously improve the efficiency of their internal and external processes for market competitiveness. Some become successful and more efficient by the value-adding activities reflected in their internal value chain than other competitors. As a key asset, knowledge supports the value-adding activities from internal creation to external realization. Thus, knowledge flow has become a valuable process within a firm and between firms (Lin, et al., 2012; Bhosale \& Kant, 2016).

Vast studies deem the knowledge flow as a key to improve a firm's competitiveness and effectiveness (Abecker, 1997; Klint \& Verhoef, 2002; Lee \& Han, 2009; Lu, et al., 2010; Lin, et al., 2012; Frey, et al., 2012; Cleveland, et al., 2015; Bhosale \& Kant, 2016; Dalkir \& Beaulieu, 2017). It is usually associated with knowledge capture, reuse, transfer and management (Cleveland, et al., 2015; Oliveira, et al., 2015; O'Leary, 2013). These topics encompass a varied range of research regarding product developments, resulting in algorithms, procedures, models and methods. Lim, et al. (2017) pointed out knowledge as a fundamental attribute within the product life cycle and the gap between knowledge management and 
sustainable supply chain management. To address the gap, Wang \& Wang (2016) proposed a method based on Petri Net to improve the efficiency of engineering change processes. The important change factors including mechanisms, organizational structure and culture that can enable the knowledge flow for product developments have been identified (Ghaedian \& Chen, 2012). It is found that the most barriers to knowledge flow in different stages of knowledge management depend on the members of the firm (Lin, et al., 2012). Furthermore, the key actors that enable the knowledge flow in a firm can be identified by the modeling approach (Bhosale \& Kant, 2016). The existing findings indeed enhance our understanding in managing knowledge flow and posit the need of contextual visualization of the relationships among the actors. However, it is yet to know how to create a customized procedure or method to improve a firm's knowledge flow for product development.

\section{Internal Value Chain and Knowledge}

A value chain is known as the system of activities that interact with each other (Cleveland, et al., 2015). The vast concept of value chain can be understood at industry level (external) and a firm level (internal).

According to Grigorescu (2015), an external value chain is a pathway in which a firm interacts with its suppliers, distributors and customers. The external value chain is known to consist of the important supply and distribution processes at the industrial level (Bachrodt \& Smyth, 2004), which should allow the firm to increase and improve own capabilities (Grigorescu, 2015). On the other hand, Spence \& Kale (2008) referred to internal value delivery process as the firm's internal value chain. A firm's internal value chain is seen as "one part of a larger system in which value is created by managing a virtuous cycle of stakeholder expectations, successful brand delivery, satisfaction and loyalty that combine to generate sustainable and superior industry returns" (Helm \& Jones, 2010, p.580). For example, Elloumi (2004) pointed that the internal value chain of an online learning institution consists of all physically and technologically distinct activities within the institution that add value to the learner's experience. In managing the internal value chain, Smirnov (2011) proposed an internal value chain model based on Porters \& Millar's (1985) traditional value chain model focused on how this system works within a firm that develops products and commercializes them. Certainly, a firm usually consists of many functional departments and each department is considered as one activity of the internal value chain. Every department executes a set of activities to acquire, manipulate and channel information (Cleveland, et al., 2015). Smirnov's model (2011) is designed to improve the firm's organization structure. For this purpose, the different departments of a firm should know their roles within the internal value chain (Spence \& Kale, 2008). This is also our focal point of study at the firm level, but with a mission to improve the knowledge flow.

A firm's activities are favored to be performed at a lower cost and to lead to market differentiation in order to gain competitive advantage for fulfilling customer needs. O'Leary (2014) found out that consulting firms are those who are most interested in knowledge management. Moreover, it is posited that to improve the knowledge flow is a way to increase the firm's performance (Molina, et al., 2007; Bhosale $\&$ Kant, 2016). Sharing knowledge efficiently is a relevant factor in order to add value for an improved internal value chain.

Knowledge is known for its dynamic essence, as it circulates from the point of origin to the point of consumption (Howlett, et al., 2012). Knowledge as useful information requires either theoretical or practical learning of a determined issue. It is certainly the object by which interested groups interact with each other (Gherardi \& Nicolini, 2000). Thus, it is the source of lasting competitive advantage within a market which is constantly changing (Nonaka, 1991). There are two types of knowledge, according to Nonaka (1991). One is in words, numbers or other data that are easy to communicate. This is the explicit knowledge which is formal and systematic (Garstenauer, 2014). The other is through tacit knowledge, which refers to the knowledge acquired by executing actions and experiences that an individual has obtains. This can be hard to formalize (Howlett, et al., 2012). However, if formalized, the tacit knowledge can be spread and shared faster than the explicit knowledge (Oliveira, et al., 2015). 
Undoubtedly, a determined product or service is constituted by data and information, and it is combined with experience and other skills, which are transformed from both types of knowledge. As knowledge is an important asset to competitive advantage, one key for a firm's success is the know-how of strategic management of knowledge dynamics across the organization (in-house) (Lee \& Yang, 2000; van Zyl, 2003; Howlett, et al., 2012).

\section{Strategic Management of Knowledge Flow}

Knowledge flow is understood as the process of transferring knowledge across determined interested groups from the place where it is generated to the place where it is needed to be applied. An effective knowledge flow within a firm requires proper internal mechanisms to administrate knowledge (Lin, et al., 2012; Cleveland, et al., 2015). Transferring knowledge is known as a decisive factor during the process of moving a product from the suppliers to the customers (Blome, et al., 2014; Lim, et al., 2017). In this regard, KM approaches are found to positively affect the firm's performance (Molina, et al., 2007; Blome, et al., 2014; Leszczyńska \& Pruchinicki, 2015; Lim, et al., 2017). KM approaches can be applied to strategically manage the use of information. They can help to identify and leverage collective knowledge within a firm. The purpose is to provide an efficient flow of knowledge to the right people/groups (Tajgardoon, et al., 2015; Dalkir \& Beaulieu, 2017). The benefits of applying a KM approach includes knowing how to manage the knowledge strategically within a firm (van Zyl, 2003). It extends over multiple disciplines within a firm by the knowledge exchange between participants (Awad \& Ghaziri, 2004; Kuan, 2005)

KM approaches exist within a large interdisciplinary field. They include a set of different cycles, models, tools and strategies among others (Vail, 1999). Therefore, to customize the use of its properties for the certain firm's performance is a necessity. As a basis, it is essential to identify the knowledge dynamics within the firm before optimizing it. The KM cycle can enable the identification of the knowledge flow in terms of the KM process (Alavi \& Leidner, 2001). However, the KM cycle cannot be structured without tools. KM has a set of both IT and non-IT tools and techniques (Dalkir \& Beaulieu, 2017), which can be applied according to the firm's needs and preferences. Some examples of these tools are: knowledge worker competency plan, knowledge mapping, knowledge portal, video sharing and so on (Dalkir \& Beaulieu, 2017). In our case, we further adopt knowledge mapping as the non-IT tool in order to have an overview of the knowledge flow.

Based on the above, we address our identified problem in the following steps:

Step 1. Establishing the KMCycle

The KM cycle is known as a set of processes that extend over multiple disciplines within the organization, giving an overview of the actions that a firm applies to manage knowledge (Alavi \& Leidner, 2001; Evans, et al., 2015). In our context, we use the processes established by Alavi \& Leidner (2001): (i) creation, (ii) storage, (iii) transfer and (iv) use. (i) Knowledge creation consists of developing new knowledge by improving existing ways to perform activities, reasoning and observing existing knowledge within the real world. (ii) Knowledge storage consists of collecting and saving data and information by using physical or digital means. (iii) Knowledge transfer refers to moving knowledge from the sources to those who need it (Kuan, 2005). Transfer occurs between individuals, between groups, from individuals to groups, from groups to the organization and across groups. (iv) Knowledge use consists of the respective knowledge application reflected in tasks, procedures or other organizational routines (Alavi \& Leidner, 2001; Evans, et al., 2015).

\section{Step 2. Mapping the Knowledge Flow}

Knowledge mapping is a tool that reveals how knowledge flows within an organization (Dalkir \& Beaulieu, 2017). There are three sub-steps:

1. Identify the knowledge flow actors and roles: The knowledge flow depends on everyone who is involved in the process of transferring knowledge through the acquisition and provision of information according to their needs and tasks (Musial, et al., 2013; Wang \& Wang, 2016). 
According to Szulanski (1996), the transfer process initiates first when the source unit decides to transfer it. Second, there are linkage units that apply certain resources to make the flow of knowledge possible between the source unit and the recipient unit. The categorization of those actors that participate in the knowledge flow process is possible by the existing approaches (Bhosale \& Kant, 2016; Wang \& Wang, 2016). Therefore, we aim to identify who are involved in the transfer process of knowledge, and then which actors are the source, linkage and receiver units. In this way, there will be a clear overview of who acquires and who provides knowledge across the firm's internal value chain.

2. Filter Information: Within KM, information filtering is the function that allows the firm to go through large amounts of information to gather what is relevant and needed (Leszczyńska, et al., 2015; Dalkir \& Beaulieu, 2017; Juzgado, 2010). Juzgado (2010) presented the information extraction as the attribute to capture and understand the information needed to consolidate knowledge. In order to have an overview of what information should be transferred, it is necessary to extract the relevant information by classifying the content in different groups. Once information is extracted, it needs to be filtered and grouped in order to avoid information overload (Juzgado, 2010). It is particularly helpful to keep track of what information is being generated, stored, transferred and used during the process (Juzgado, 2010). The relevance of classifying information is to distinguish what is the information needed for the different actors within the firm's internal value chain.

3. Identify knowledge needed to be transferred (transfer the right knowledge): The knowledge transfer usually depends on human interactions. The process of knowledge transfer is a challenge in the multidisciplinary teams/departments because knowledge is usually defragmented across the organization (Alavi \& Leidner, 2001). When the source proceeds to provide information, we should know what the receiver needs and should have. In order to know what knowledge is needed to be transferred and how it flows within a determined organization, it is necessary to determine and coordinate who needs what knowledge (Vail, 1999; Gherardi \& Nicolini, 2000). Once we have identified the KM factors, it is possible to address the identified problem of this study - to optimize the firm's knowledge flow across the departments of a firm.

\section{Conceptual Framework}

Based on the above, we structured a conceptual framework in order to offer the guidelines for optimizing the firm's product knowledge flow across the firm's internal value chain (See FIGURE 1). $\mathrm{KM}$ cycle processes and its tools aim to jointly contribute to the effective improvement of the knowledge flow within an internal value chain. In addition to the literature specifications of the KM approach, the conceptual framework also reflects the components of the firm's current knowledge flow situation. Both aspects are taken into consideration to serve as the basis for developing the customized procedure for the firm's internal value chain.

FIGURE 1 shows the framework components grouped into three sections. The first section is the KM approach, which shows the processes of KM cycle and the three identified aspects of the knowledge mapping. The second section of the framework contains both the firm's current situation and the challenges that concern the product knowledge flow. The identification of these factors within the firm is based on the relevant literature. In this way, the firm's current situation in managing knowledge and the challenges for optimizing the knowledge flow is referencing the know-how of KM literature, and the gaps of improvement of their knowledge flow can be identified. The final section of the framework represents the customized procedure, which consists of the four basic components of KM processes to fill the identified gaps. 


\section{RESEARCH METHODLOGY}

We conducted the real-life case study to apply the conceptual framework for a customized knowledge flow across the firm's internal value chain. The case data were collected based on three rounds of face-toface interviews in the case firm. The interviewees were carefully selected based on their knowledge sufficiency of the product and services, as well as the knowledge circulation of the firm.

The first-round interview was to identify and validate the problem of the study. It was conducted with two performance leaders of the case firm who are in charge of building the desired organization's culture.

The second-round interview was performed to get an overview of the current product knowledge flow across the case firm's internal value chain. We identified the relevant activities that the firm performs to manage product knowledge and the current knowledge transfer actors. It consisted of individual face-toface interviews with seven interviewees. Six of them were directors of the six different departments in the case firm's internal value chain: marketing, development, $\mathrm{R} \& \mathrm{C}$, sales, customer service and logistics. They have the right knowledge about the extant activities of managing knowledge within their own departments and across all the departments of the case firm's internal value chain. The seventh interviewee was one of the product owners, who has the complete responsibility for one of the firm's products.

\section{FIGURE 1}

\section{CONCEPTUAL FRAMEWORK}

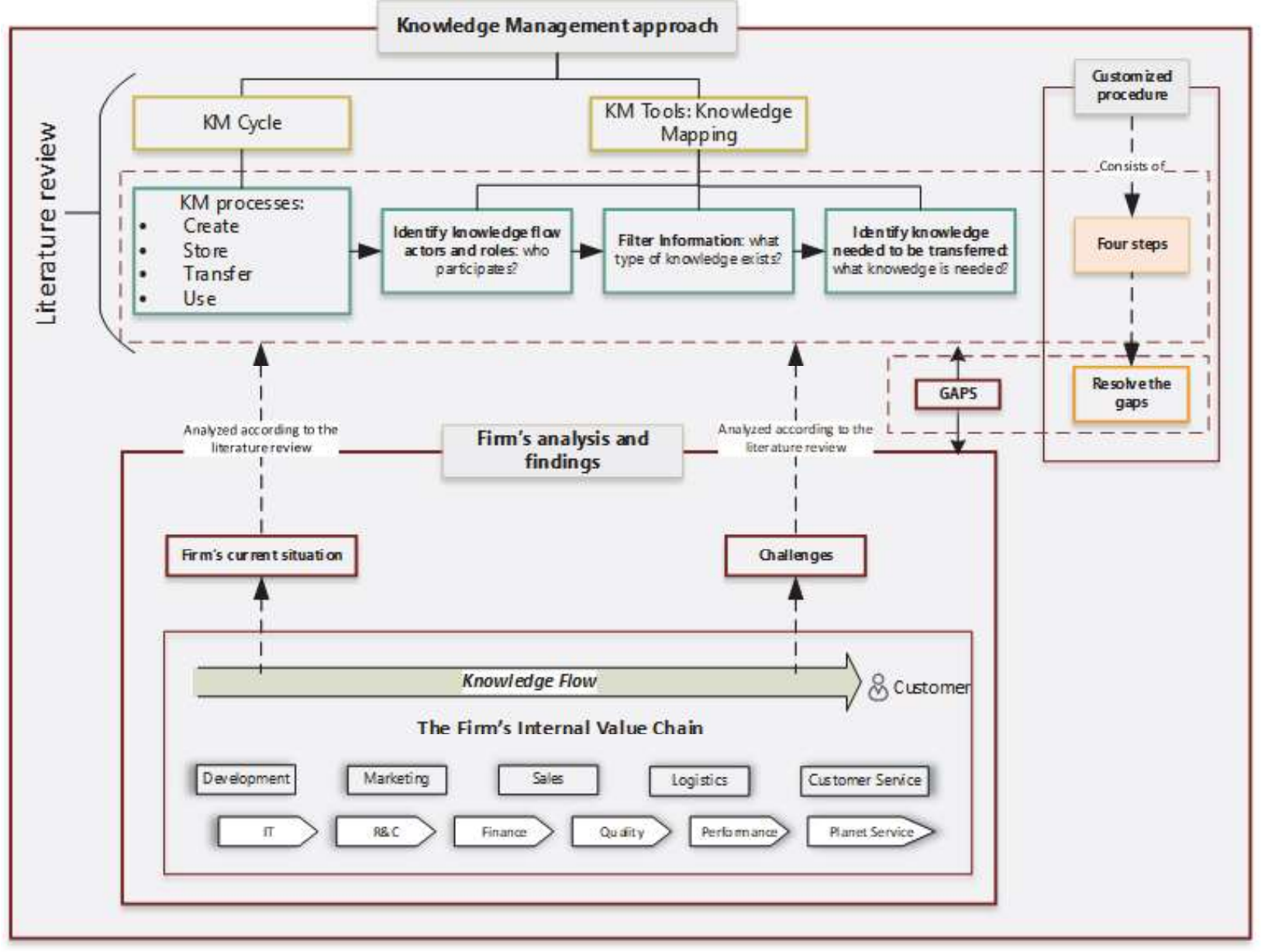


The third-round interview was conducted to identify the challenges that the case firm has been facing while transferring knowledge across the internal value chain. In this round, we conducted individual faceto-face interviews with the chief performance officer, the quality director and the product owner.

During the second and third rounds of interviews, we conducted the extensive literature overview to investigate those critical factors that affect the knowledge flow in a firm's internal value chain and know how in improving the efficiency of the knowledge flow. Based on both findings from case data and literature review, the gaps from improving knowledge flow in the case firm's internal value chain can be identified. With a focus of the resolving the gaps, the customized procedure can be outlined as the solution. As a summary, the research methodology of this study is described in FIGURE 2.

\section{FIGURE 2 \\ RESEARCH PROCESS FOR THE CUSTOMIZATION OF THE KNOWLEDGE PROCEDURE}

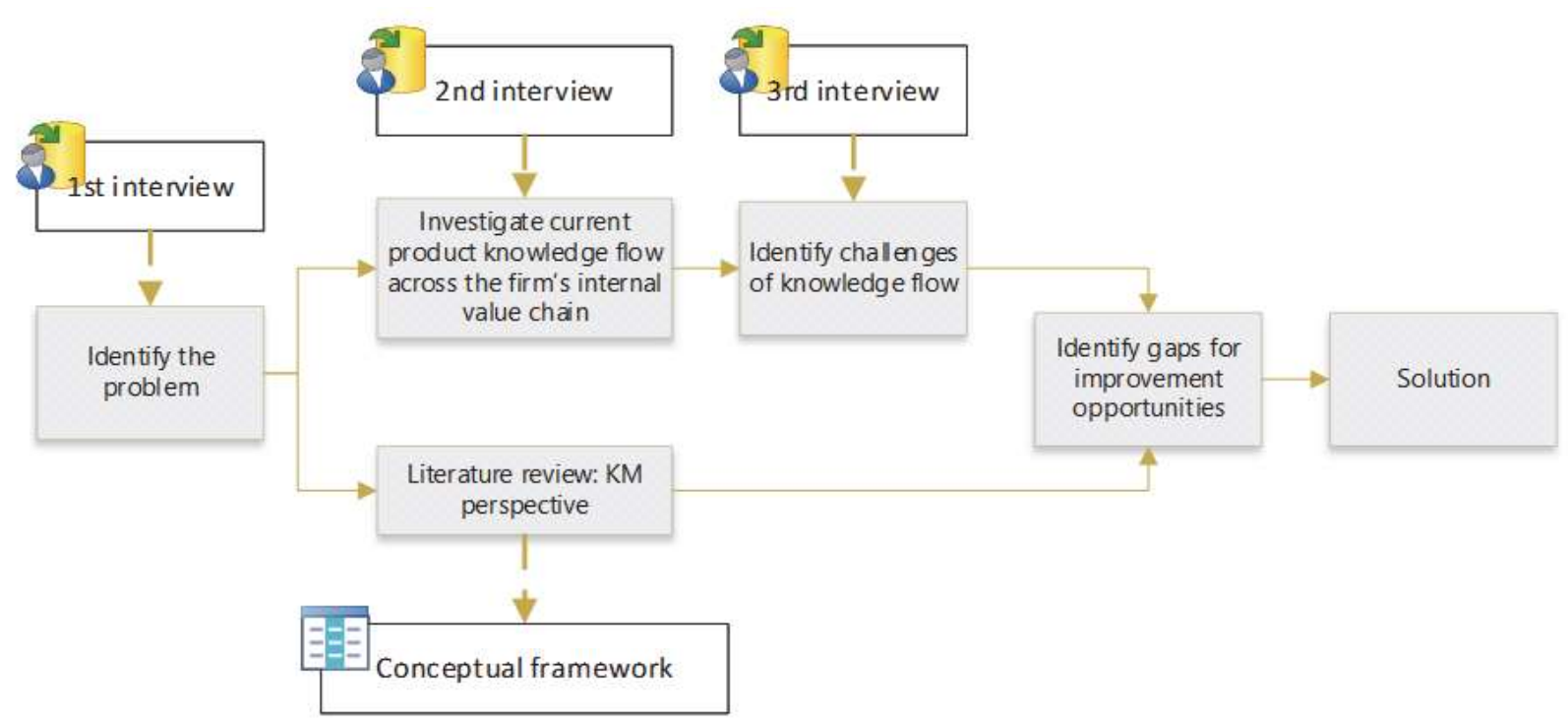

\section{CASE ANALYSIS AND FINDINGS}

\section{Overview of Current Product Knowledge Flow Across the Firm's Internal Value Chain}

Based on interview data, we analyze the firm's current product knowledge flow. The data are collected separately in different rounds of interview, and all the data are collectively analyzed and presented in a visual diagram. The visual diagram, shown in FIGURE 3, illustrates the knowledge flow throughout the case firm's value chain. The flow diagram was the first initiative for the case firm to visualize the existing knowledge flow and help to organize, understand and further discuss the situation for improvements.

The existing knowledge flow diagram highlights the current activities that the firm executes to manage knowledge and the actors that intervene in the knowledge transfer. Further, we use the conceptual framework to conduct the case analysis. The finding is presented below.

\section{Current Activities to Manage Product Knowledge}

The firm has a focus of quality throughout the internal value chain from the development phase and all the way to a satisfied customer. The firm has had the respective activities to manage their knowledge. We identified some of these activities that the firm executes to make the flow of knowledge possible across its internal value chain. We group them in the KM processes to provide an overview of the activities (Awad \& Ghaziri, 2004): (1) Create: The firm has determined departments in charge of creating, modifying and updating the products and services. Those departments are constantly creating the relevant knowledge. Meanwhile, the product developers and owners analyze the customer's feedback and needs to improve the product's performance for the customers' satisfaction. (2) Storage: The firm has a tool to 
store a significant amount of knowledge and information generated. The quality system is an encyclopedia of information available for all the employees. The storage system contains all types of media used for training, such as manuals, instructions, guidelines and policies among others. It aims to help employees find information to perform better, so as to improve the working processes and quality. (3) Transfer: The firm's departments that generate product knowledge, have distributed the news about the product to the interested groups of the firm's internal value chain. There are several existing ways to transfer product knowledge. One example is that some department have the periodically communicated current events through meetings. When it is necessary, the respective departments would provide individual and collective trainings to certain workers and groups that need to learn more about the properties of the product. These sessions are executed by using tools such as tutorial videos and courses among others. (4) Use: As the product information is provided, those employees who receive it should apply it. The information and knowledge about the product should be transferred to the next interested party in the internal value chain, and then to the customer. To transfer the information is associated with a good understanding what to be received, and an effort to explain the information efficiently. However, it is found that a large amount of product knowledge that is supposed to circulate throughout the firm's value chain needs to be improved.

\section{Current Knowledge Transfer Actors}

According to Szulanski (1996), the product knowledge flow depends on three units that transfer the information across the departments of the internal value chain: source, linkage and receiver. In this case study, FIGURE 4 illustrates the identified actors within the knowledge transfer process. We found that the product owner is the person with the absolute responsibility for everything related to the product in the whole internal value chain, including the customer's satisfaction.

The departments of development, research and creativity $(\mathrm{R} \& \mathrm{C})$ and IT are in charge of executing modifications and adding features to current and new products. Development, R\&C and IT are the source unit, in addition to the product owner. If needed, the department of quality is the linkage unit that should provide training to the receiver units by different learning methods in order to ensure the well-absorbing of the information. The departments that have a direct relationship with the customer are those proving customer service and sales. They are the receiver units that will use the knowledge that has been generated. However, there are other departments of the firm's internal value chain that can be receiver units as well. The remaining departments are the other interested parties that can either receive or provide product information from/to the source units. This depends on their interest in communication relevant factors of their fields that affect the product properties.

\section{Challenges of the Knowledge Flow Across the Firm's Internal Value Chain}

Based on the overview of the firm's current knowledge flow, its main influential factors and actors and the interview data, we identify the following challenges.

\section{Understand How the Firm Manages the Knowledge Flow}

Since the firm implicitly executes activities to manage knowledge without a defined systematic approach, it is difficult to recognize where they can execute determined actions to improve their knowledge flow. The challenge is to identify and explicitly represent how the processes for managing knowledge are organized, and how they interact with each other in order to understand how the knowledge flows within the internal value chain in an effective manner. In addition, the processes of knowledge cycle we identified should be executed by the determined actors. Therefore, the challenge also includes the explicit identification of who participates in the knowledge flow.

\section{Manage the Large Amount of Knowledge}

The third round of interviews disclosed that the firm constantly generates a significant amount of product information and knowledge. To fully capture large amounts of information and knowledge can be a daunting challenge. The firm's employees often have difficulties in acquiring a small portion of information that is relevant for them to apply. The challenge here is to carry out the right amount of information to the interested parties. Then they need a way to know how much information must be 
acquired and provided. This challenge is related to the next one, regarding the consistency of the knowledge flow.

\section{Keep the Consistency of Knowledge Flow}

The firm's culture prompts that relevant information and knowledge do flow across the internal value chain. However, the current way they transfer product information and knowledge represents a challenge for the firm. As information and knowledge accumulates continuously, they can be delivered incompletely and/or out-of-date. Sometimes, they are even unnecessary for the certain individual or group to receive. There are cases where some information simply disappears because it is neither transferred nor used. Furthermore, the firm has not known where knowledge was disintegrated. These factors can alter the trustworthiness of the product properties, which is at the final cost of the customer's quality service. The lack of knowledge where it is needed leads to the use of additional time to ask questions and receive answers. Some knowledge users prefer to seek help from experts in the field or one of the information sources instead of consulting documents or other explicit forms of knowledge. In short, the firm is facing a key challenge to track and keep the consistency of the knowledge flow to avoid the cost of incomplete, inaccurate or unnecessary knowledge transfer.

\section{Gap Analysis}

Based on the identified challenges in practice and possible knowledge flow management in theory, the gaps are highlighted below.

\section{Lack of an Explicit KMCycle}

We found that the firm does not have an explicit overview of the current knowledge stages to help identify the product knowledge flow. The activities that the firm applies in managing knowledge are implicitly executed as a natural and ongoing set of tasks. The gap has repercussions in managing the knowledge flow as the firm is unware of where and why determined product knowledge disappears along the value chain.

\section{Establish the Actors' Roles within the Knowledge Flow}

We discovered that since the knowledge flow is an implicit process, the actors that participate in it are implicit as well. In order to improve the knowledge flow from a KM perspective, it is indispensable to identify the actors and the role of them: Who creates? Who stores? Who transfers? Who uses the product knowledge?

\section{Need for Synthesizing the Product Knowledge}

There is a lack of synthesizing among the large amount of product knowledge. The lack of this practice makes the provision, acquisition and application of knowledge, a complex activity.

\section{Identify the Knowledge Needed to Be Transferred}

It is unknow what knowledge the interested parties across the firm's internal value chain need, not only to execute their tasks and achieve their goals, but also to ensure that customers receive all the necessary product information. The source units of knowledge may sometimes ignore the information that the receiver units really need to acquire. Therefore, there is an uncertainty about the information they should provide. In the case of internal receivers, once the sellers receive the product information, they become the source units for the customers. To get their job done, the sellers may consider that the perceived information is enough for customers, while other departments of the internal value chain consider that the information given is not enough. The firm has adept to create and store knowledge, but there is lack of systematic mechanism of what knowledge flows, should flow and by whom (what knowledge is transferred, should transfer and by whom) within the internal value chain.

\section{THE CUSTOMIZED PROCEDURE OF KNOWLEDGE FLOW FRAMEWORK}

An efficient knowledge flow is achieved by applying an internal mechanism to administrate the knowledge (Garstenauer, et al., 2014). We propose a customized procedure for the firm, with steps based on our synthesis of the relevant literature as illustrated in the conceptual framework. 


\section{Goal of the Customized Procedure}

Through the customized procedure, we want to emphasize the relevance of having a systematic mechanism that facilitates the knowledge flow across the firm's internal value chain. The goal of this procedure is to create a systematical guide for the identification of the firm's current knowledge flow, so that the firm may easily to find the critical factors that hinder the knowledge circulation. This procedure has a set of four steps in response to the identified gaps of managing knowledge flow within the firm. It was customized to fit the firm's existing way of working in order to avoid cost of significant changes. The steps of the procedure can be used as the guidance for the firm have a clear overview of the knowledge flow situation across the internal value chain. By applying it, the firm can explicitly: (i) identify the processes performed to manage knowledge, (ii) identify who intervenes and their roles, and (iii) classify the product knowledge. Once the firm has identified and classified these mentioned aspects, they can (iv) identify who needs what information. Then the interested parties within the firm will know what knowledge should be transferred.

\section{First Step: Identify the KM Cycle}

We found that the firm's existing activities of KM can be represented by the KM cycle developed by Alavi \& Leidner (2001), although it is necessary to customize it in order to reflect the firm context. Therefore, the first step consists of identifying the KM cycle that fits to the product knowledge flow across the firm's internal value chain. FIGURE 5 illustrates an example of a possible customized cycle that consists of create, store, transfer and use of knowledge within the firm. What makes this cycle different from others is the interaction between the processes. As knowledge flows across different departments of the internal value chain, from the point of creation to the point of use, the transfer process is performed more than once between the create and use processes. The store process is performed several times as well, because as some actors create, transfer and use information, they store it in different devices or databases. Some examples are their quality system, e-mails, documents like manuals among others.

To implement this model, it is important to learn what the firm is doing with the existent knowledge and how they perform each process. The KM cycle enables the identification of how each process affects the firm's goals. Once the KM processes are defined, we need to identify who participates and who executes the respective processes.

\section{Second Step: Identify KM Actors and Their Roles}

The identification of the actors who have initiated and who participated in the transfer process is found to enable the understanding of who should provide and who should receive information or knowledge. The second step of the procedure suggests the identification of who in the internal value chain owns the product knowledge source unit, provider unit, linkage unit and receiver unit. The goal of this step is to be aware of which actors intervene and what their roles are within the KM processes, shown in FIGURE 6. Then, we shall ask: Who creates it? Who stores it and where? Who uses it? and who transfers it?

\section{Third Step: Classify Product Knowledge}

The firm faces the challenge of managing the large amount of information. According to the literature review, we disclosed that filtering the information by its classification helps to deal with this challenge. The goal of this step is to extract from the whole pool of information and knowledge to collect what is needed to be used across the firm's internal value chain. Classifying the product knowledge helps to have a better organization and control of the knowledge that should be transferred. It consists of identifying the knowledge that is required to reach customers with the product's properties.

FIGURE 7 illustrates an example of product knowledge classification. The different types of product knowledge flow through the firm's internal value chain and all the way to the customer. This is the classification by the firm's product owner who is the main source and provider of the information and knowledge of the product. 
FIGURE 3

\section{EXISTING KNOWLEDGE FLOW DIAGRAM}

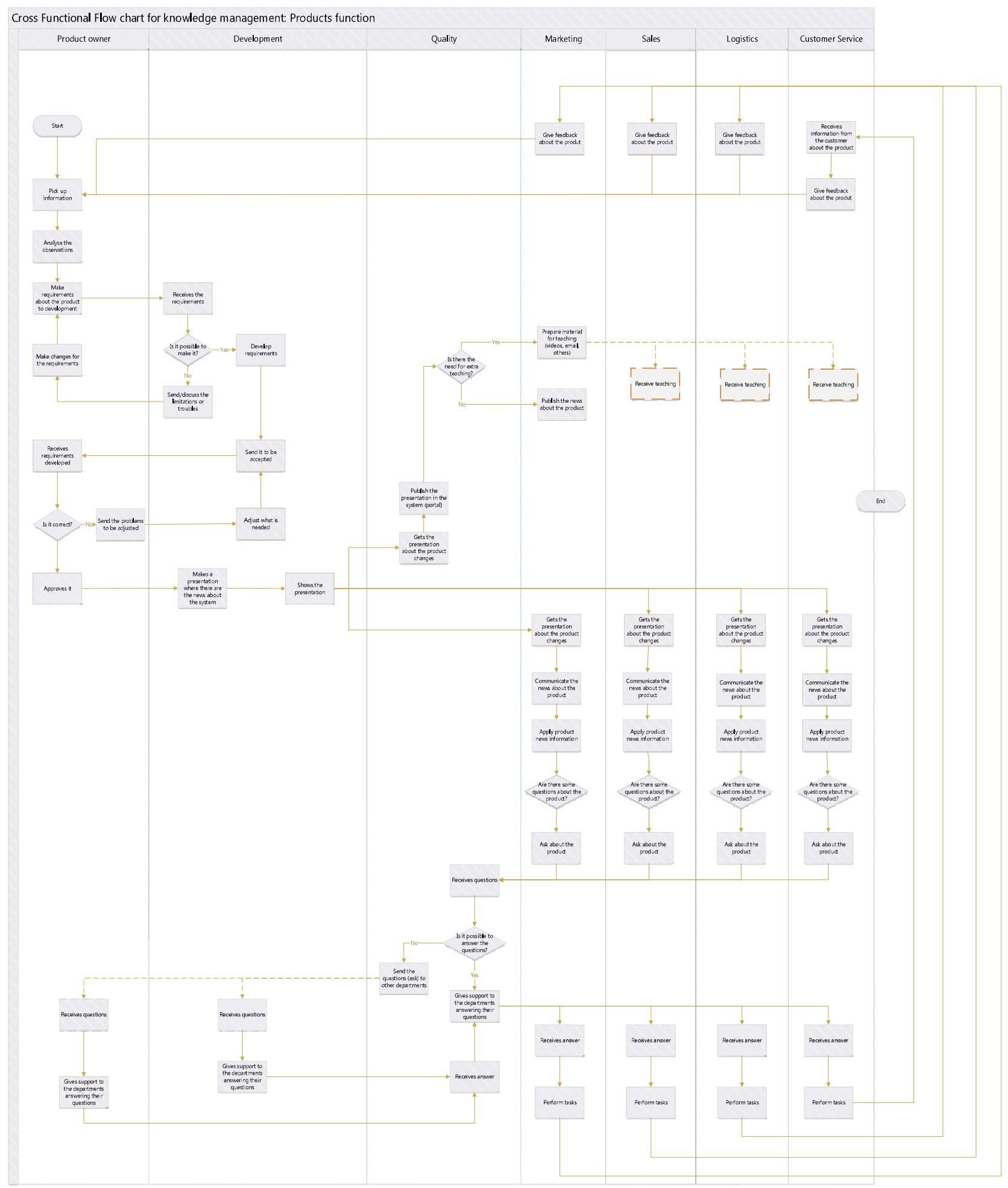


FIGURE 4

\section{EXAMPLE OF DEPARTMENT'S CLASSIFICATION IN TRANSFER UNITS}

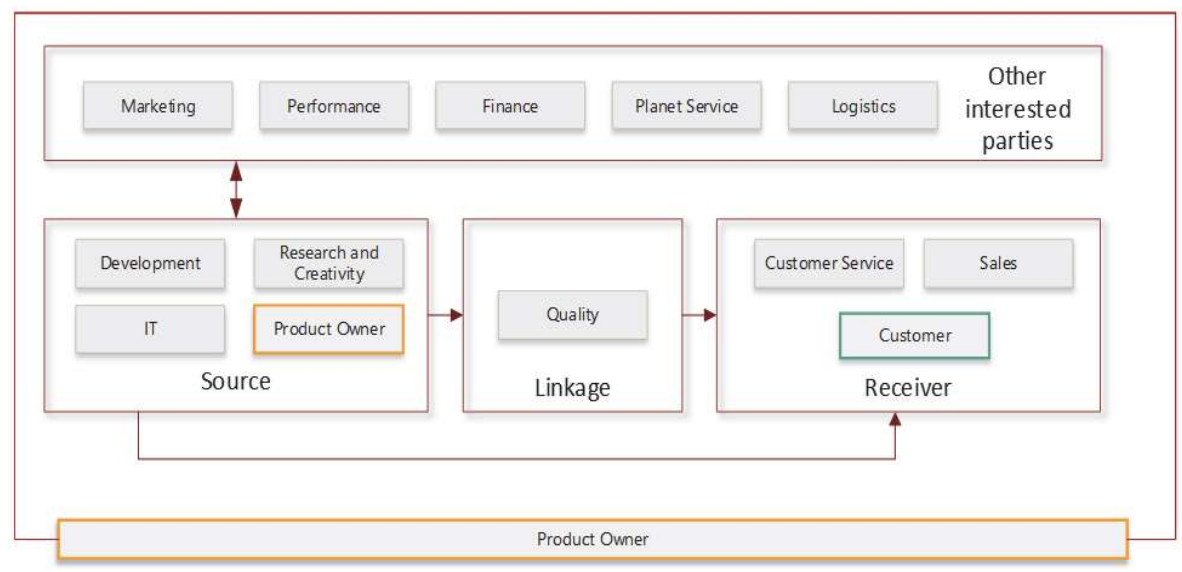

FIGURE 5

EXAMPLE OF CUSTOMIZED KM CYCLE FOR THE FIRM

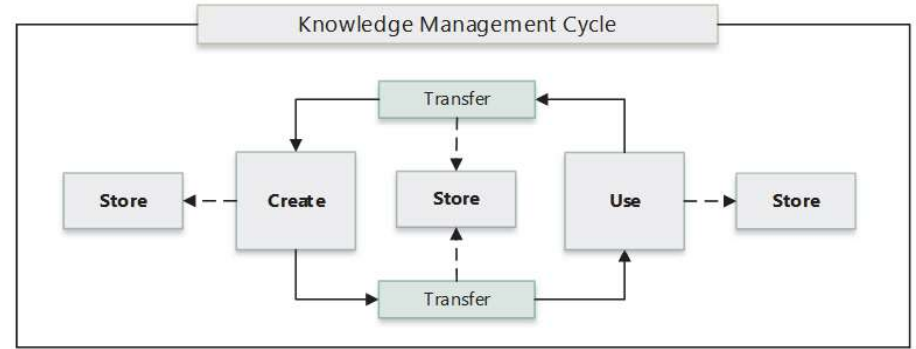

FIGURE 6

EXAMPLE OF THE FIRM'S KM CYCLE: ACTORS AND ROLE

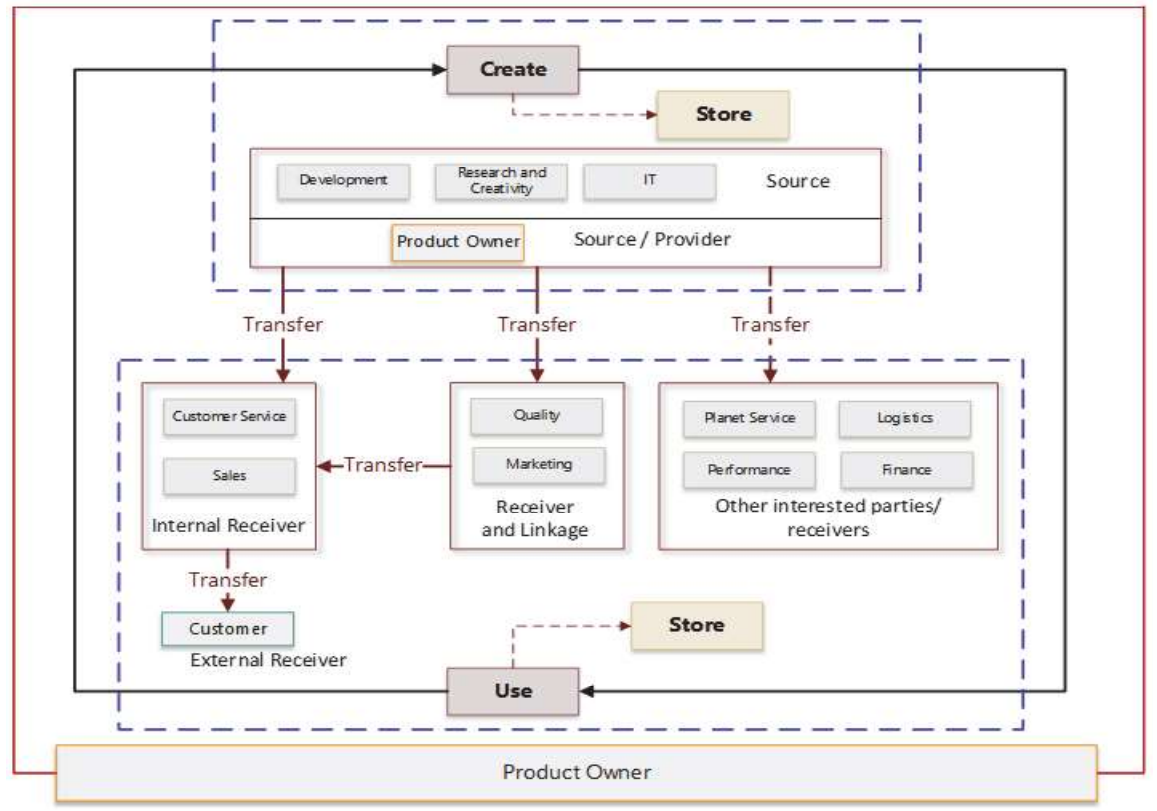




\section{Fourth Step: Identify the Knowledge Needed to Be Transferred}

First, it is to identify what knowledge is used across the internal value chain. We can use the information that we have identified in the previous three steps: the KM processes, the knowledge flow actors and their roles and the existing type of product information. FIGURE 8 is a symbolic diagram that illustrates the dynamic of this step.

\section{FIGURE 7 \\ EXAMPLE OF CLASSIFICATION OF PRODUCT KNOWLEDGE}

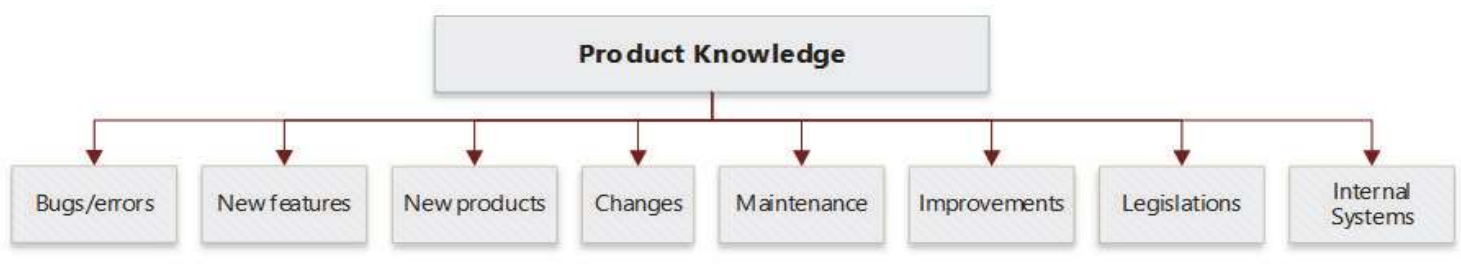

FIGURE 8

EXAMPLE OF THE DIAGRAM: OVERVIEW OF THE PRODUCT KNOWLEDGE FLOW

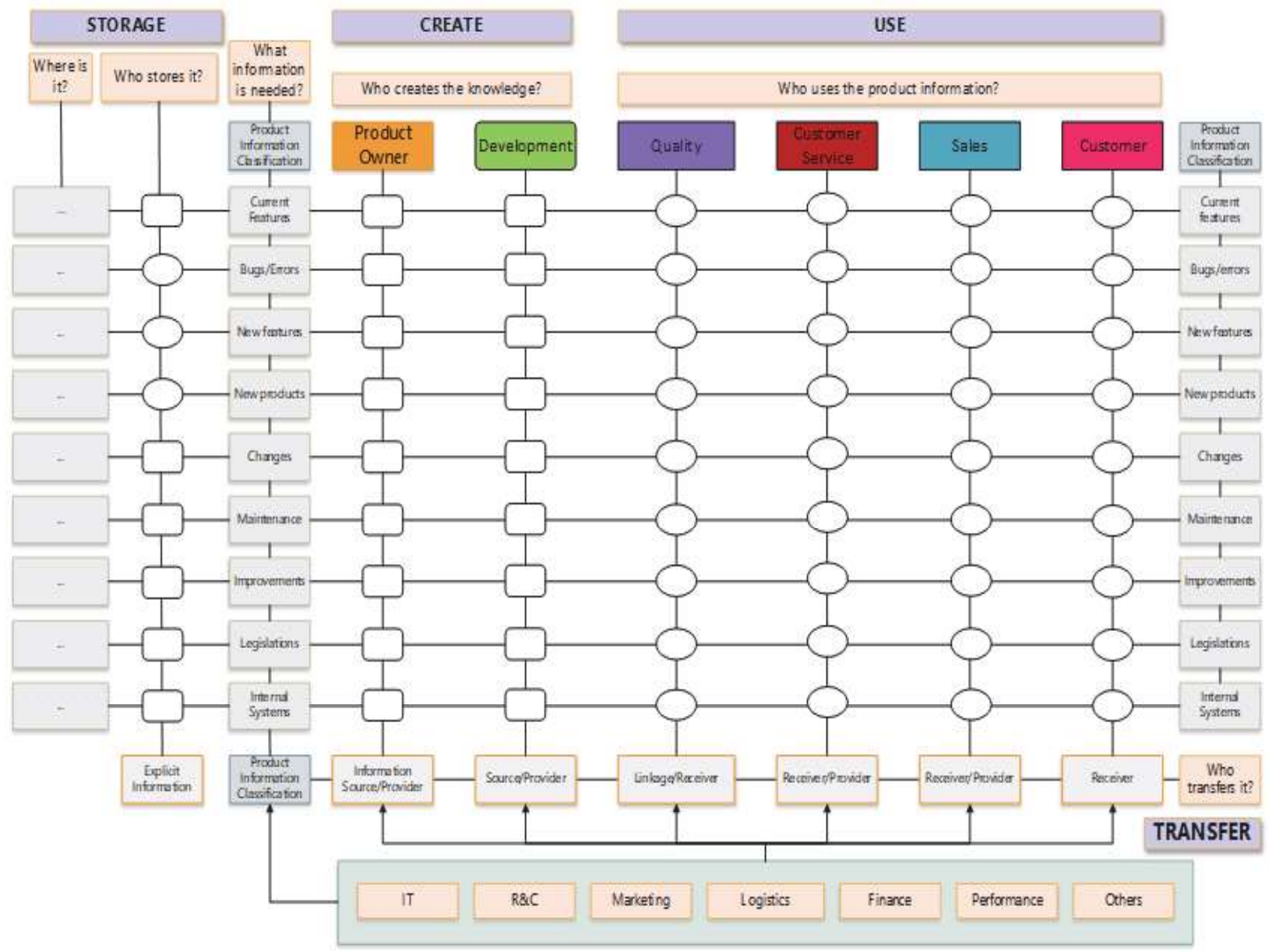


The diagram is an example of a matrix that we designed to help the identification of who needs what type of knowledge, where this product information is stored and by whom, and what the role of each actor is within the transfer process.

To use the diagram, it is necessary to identify the type of product knowledge that is to be transferred throughout the internal value chain, the actors that intervene in the process of transferring knowledge and their roles within the KM processes. This depends on the findings from the first three steps mentioned above.

In order to differentiate the KM actors in the diagram, each of them has a determined color in order to have a better visualization of their participation with the information and knowledge flow. It is noticeable that the matrix has two kinds of nodes that are an intersection between each KM actor and classified information. The first node has the shape of a rectangle which is for the actors that create the knowledge. The second node has the shape of an oval which corresponds for the actors that use the knowledge. The lower part of the diagram describes the role of the KM actors regarding the process of knowledge transfer. In addition, there is a set of the other KM actors that intervene in the knowledge flow, but not as direct creators or direct users of the product knowledge. In this case, this set of actors are visible in order to recognize their presence within the value chain, their relations with the different classified information and their roles transferring information.

Based on the structure of the diagram, we can further work on the nodes representing the answer to the formulated questions. The nodes must be filled out with the same color of the actor's column if the actor creates, uses or stores the information/knowledge of the product. The example of a fill out diagram is shown in FIGURE 9.

FIGURE 9

\section{EXAMPLE OF A FILLED-OUT DIAGRAM}

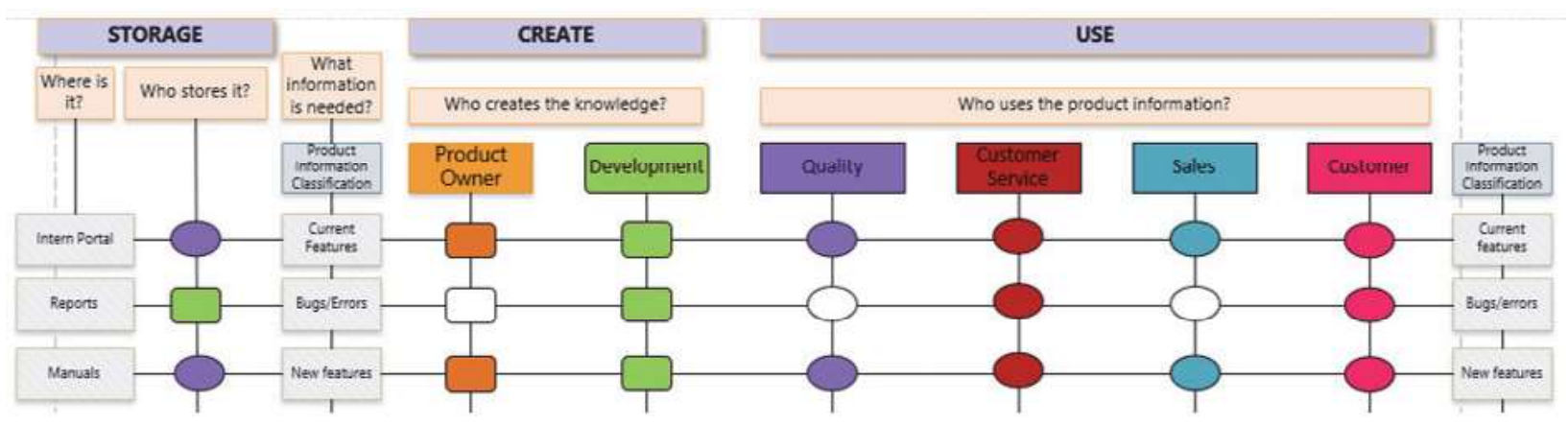

Once the diagram is completely filled out, the firm has an overview of the product knowledge flow within the internal value chain of the firm. The overview of the product knowledge flow reveals:

- The type of product information that is needed to transfer and used across the internal value chain.

- The actors and their roles within the knowledge transfer: who the source, linkage and receiver units are.

- The actors and their roles in respect to the $\mathrm{KM}$ creation, storage, transfer and use.

- Where the knowledge is stored.

- The availability of knowledge depending on the place where it is stored.

- Which actor needs what type of product knowledge.

\section{CONCLUSIONS}

This study aimed to resolve the customization of a systematic mechanism for facilitating the knowledge flow across the firm's internal value chain. Based on the extensive literature review and the 
case study, the customized procedure for improving knowledge flow across the firm's internal value chain is outlined. The journey of such a customization may serve as a guidance for similar issues for other firms in industries.

There has been a growing need for customizing procedures or processes by utilizing the KM approaches to rescue the value chain optimization in a specific firm's context. The study shows that KM approaches can pave the way for developing the customized systematic mechanism to improve the knowledge flow across the different disciplinary teams within a firm. This analysis was reflected in a conceptual framework, which includes: a) a KM cycle to represent the processes that exist and are needed to manage knowledge, b) knowledge mapping, a KM non-IT tool consisting of a set of questions that help to determine what knowledge flows within a firm and who participates in this process, and c) a conceptual representation of the firm's analysis and findings. The usage of conceptual framework has been demonstrated in the real-life case.

The conceptual framework was the basis for developing the aforementioned customized procedure as a solution to the main problem. The customized procedure is a solution that was thought to fit the firm's current way to work and to fill the identified gaps in practices. It consists of four steps that can facilitate their knowledge flow by: a) identifying the processes executed to manage knowledge, the actors and their roles of transferring and managing knowledge, b) classifying information and identifying the knowledge that is used by the departments of the internal value chain. Through this procedure, we have contributed to:

- Emphasize the application of the KM approach as the efficient way to improve the knowledge flow across a firm's internal value chain, since we identified guidelines that can be adjusted to the firm's context.

- Establish a way to manage large amounts of product information in order to avoid overload. This was done by classifying the information that should flow within the firm.

- Make the knowledge flow an explicit process. This provides guidelines to identify what knowledge is used by whom. Then, the interested parties within the internal value chain know what knowledge they have to provide and acquire. This information plays an important role during the transfer of this resource. Thus, this overview serves as a tool to have a degree of control of the product knowledge that the firm is generating and using.

The customized procedure sets the foundation to introduce the KM approach to systematically manage a firm's internal value chain. It can be an ongoing effort for the firm that does not require significant changes in its daily activities. A future research may extend the scope to the firm's desired knowledge flow to optimize its internal value chain. Based on the demonstrated framework and customization journey in this study, the dynamic gap analysis between the current knowledge flow and desired knowledge flow is likely to help identify what knowledge is and what is not going to add value across the internal value chain in the future for further optimization.

\section{REFERENCES}

Abecker, A. (1997). Corporate memories for knowledge management in industrial practice: prospects and Challenges. Journal of Universal Computer Science, 3(8), 929-954.

Alavi, M., \& Leidner, D. E. (2001). Knowledge management and knowledge management systems: Conceptual foundations and research issues. MIS quarterly, 107-136.

Awad, E. M., \& Ghaziri, H. M. (2004). Knowledge management. Upper Saddle River, New Jersey: Prentice-Hall.

Bachrodt, A. K., \& Smyth, J. P. (2004). Strategic business planning linking strategy with financial reality: Linking long-term strategy with near-term financial and operational realities makes for a clearer march toward key objectives. Healthcare Financial Management, 58(11), 60-65.

Bhosale, V. A., \& Kant, R. (2016). An integrated ISM fuzzy MICMAC approach for modelling the supply chain knowledge flow enablers. International Journal of Production Research, 54(24), 7374-7399. 
Blome, C., Schoenherr, T., \& Eckstein, D. (2014). The impact of knowledge transfer and complexity on supply chain flexibility: A knowledge-based view. International Journal of Production Economics, 147, 307-316.

Cleveland, S., Mitkova, L., \& Gonçalve, L. C. (2015). Knowledge Flow in the Open Innovation ModelThe Effects of ICT Capacities and Open Innovation Practices on Knowledge Streams. In SoutheastCon 2015 (pp. 1-2). IEEE.

Dalkir, K., \& Beaulieu, M. (2017). Knowledge management in theory and practice. MIT press.

Frey, J., Bird, C. \& Willoughby, C. (2012). Human aspects of smart spaces for knowledge transfer. Innovation through Knowledge Transfer, 18, 19-29.

Elloumi, F. (2004). Value chain analysis: A strategic approach to online learning. Theory and practice of online learning, 61.

Evans, M., Dalkir, K., \& Bidian, C. (2015). A holistic view of the knowledge life cycle: the knowledge management cycle (KMC) model. The Electronic Journal of Knowledge Management, 12(2), 8597.

Garstenauer, A., Blackburn, T., \& Olson, B. (2014). A knowledge management-based approach to quality management for large manufacturing organizations. Engineering Management Journal, 26(4), 4758.

Ghaedian, S., \& Chen, B. (2012). How to support and facilitate knowledge flow in product development at Volvo Group Trucks Technology. Chalmers University of Technology, Gothenburg, Sweden. Report No. E2012:064

Gherardi, S., \& Nicolini, D. (2000). To transfer is to transform: The circulation of safety knowledge. Organization, 7(2), 329-348.

Grigorescu, I. L. (2015). Value chain analysis-basic element of an organization's competitive advantage. International conference KNOWLEDGE-BASED ORGANIZATION, 21(2), 318-324.

Helm, C., \& Jones, R. (2010). Extending the value chain-A conceptual framework for managing the governance of co-created brand equity. Journal of Brand Management, 17(8), 579-589.

Howlett, R. J., Gabrys, B., Musial-Gabrys, K., \& Roach, J. (2012). Innovation Through Knowledge Transfer. Berlin, Heidelberg: Springer.

Juzgado, P. D. B. (2010). A3 Architecture overviews. A tool for effective communication in product evolution. University of Twente, Enschede, The Netherlands, 208.

Klint, P., \& Verhoef, C. (2002). Enabling the creation of knowledge about software assets. Data \& Knowledge Engineering, 41, (2), 141-158.

Kuan, Y. W. (1999). Critical success factors for implementing knowledge management in small and medium enterprises. Industrial Management \& Data Systems, 105(3), 261-279.

Lee, C., \& Yang, J. (2000). Knowledge value chain. Journal of Management Development, 19(9), 783794.

Lee, M., \& Han, M. (2009). Knowledge value chain model implemented for supply chain management performance. INC, IMS and IDC, 2009. NCM'09. Fifth International Joint Conference on (pp.606-611). IEEE.

Leszczyńska, D., \& Pruchnicki, E. (2017). The evolution of knowledge transfer and the location of a multinational corporation: Theory and mathematical model. The Multinational Business Review, 23(2), 111-129.

Lim, M. K., Tseng, M. L., Tan, K. H., \& Bui, T. D. (2017). Knowledge management in sustainable supply chain management: Improving performance through an interpretive structural modelling approach. Journal of Cleaner Production, 162, 806-816.

Lin, C., Wu, J., \& Yen, D. (2012). Exploring barriers to knowledge flow at different knowledge management maturity stages. Information \& Management, 49(1), 10-23.

Lu, Y.Q., Zhang, J.M., \& Wang, H. J. (2010). Influence Mechanism of Service Innovation Based on the Knowledge Value Chain Model. E-Business and E-Government (ICEE), International Conference on. IEEE. 
Molina, L. M., Lloréns-Montes, J., \& Ruiz-Moreno, A. Relationship between quality management practices and knowledge transfer. Journal of Operations Management, 25(3), 682-701.

Musial, K., Budka, M., \& Blysz, W. (2013). Understanding the Other Side-The Inside Story of the INFER Project. Innovation through Knowledge Transfer 2012 (pp.1-9). Berlin, Heidelberg: Springer.

Nonaka, I. (1991). The Knowledge-Creating Company. Harvard Business Review, 69(6), 96-104.

Oliveira, M., Curado, C. M., Maçada. A. C. \& Nodari, F. (2015). Using alternative scales to measure knowledge sharing behavior: Are there any differences? Computers in Human Behavior, 44, 132140.

O'Leary, D. E. (2014). Knowledge management: An empirical analysis of reuse and productivity. Journal of Decision Systems, 23(3), 249-265.

Porter, M. E., \& Millar, V. E. (1985). How information gives you competitive advantage. Harvard Business Review, 63(4), 149-160.

Smirnov, A. (2011). Internal value chain for commercial experience companies. Norges Handelshøyskole, Bergen, Norway. MS thesis in International Business.

Spence, M. T., \& Kale, S. H. (2008). Optimising the internal value chain: Principles and practices. Journal of Management \& Organization, 14(2), 193-206.

Tajgardoon, M., Ghaem, M., Shalmani, M., \& Habibi, J. (2015). Organizational secure knowledge flow model. Information and Knowledge Technology (IKT), 7th Conference on. IEEE.

Vail, E. F. (1999). Knowledge mapping: Getting started with knowledge management. Information Systems Management, 16, 10-23.

van Zyl, C. (2003). Supply chain knowledge management adoption increases overall efficiency and competitiveness. Journal of Information Management, 5(4), 1-15.

Wang, Y., \& Wang. M. (2016). Process optimization based on knowledge flow in engineering change. Procedia CIRP, 56, 406-411.

Wixom, B. H., \& Todd, P. A. (2005). A theoretical integration of user satisfaction and technology acceptance. Information systems research, 16(1), 85-102. 